\title{
The effect of diabetic ketoacidosis (DKA) and its treatment on clot microstructure: Are they thrombogenic?
}

Pillai $\mathrm{S}^{1,2,3}$, Davies $\mathrm{G}^{1}$, Lawrence $\mathrm{MJ}{ }^{1,3}$, Whitley $\mathrm{J}^{1,3}$, Stephens $\mathrm{JW}^{2,3}$, Williams $\mathrm{PR}^{3}$, Morris $\mathrm{K}^{4}$, Evans $\mathrm{PA}^{1,2,3}$

${ }^{1}$ Welsh Centre for Emergency Medicine Research, Emergency Department, Morriston Hospital, Swansea, SA6 6NL

${ }^{2}$ Morriston Hospital, Swansea, SA6 6NL

${ }^{3}$ Swansea University, Swansea, SA2 8PP

${ }^{4}$ Cardiff Metropolitan University, CF5 2YB

\section{Abstract}

Background: Diabetic ketoacidosis (DKA) is a medical emergency with a high mortality rate and is associated with severe metabolic acidosis and dehydration. DKA patients have an increased risk of arterial and venous thromboembolism, however little is known about this metabolic derangement in the first 24 hours of admission and to assess its effect on coagulation. We therefore utilised a novel functional marker of clot microstructure (fractal dimension - $\mathrm{d}_{f}$ ) to assess these changes within the first 24 hours.

Methods: Prospective single centre observational study to demonstrate whether the tendency of blood clot formation differs in DKA patients.

Results: 15 DKA patients and 15 healthy matched controls were recruited. Mean $\mathrm{d}_{f}$ in the healthy control group was $1.74 \pm 0.03$. An elevated $d_{f}$ of $1.78 \pm 0.07$ was observed in patients with DKA on admission. The mean $\mathrm{pH}$ on admission was $7.14 \pm$ 0.13 and the lactate was $3.6 \pm 2.0$. $d_{f}$ changed significantly in response to standard treatment and was significantly reduced to $1.68 \pm 0.09(2-6 \mathrm{~h})$ and to $1.66 \pm 0.08$ at $24 \mathrm{~h}\left(\mathrm{p}<0.01\right.$ One-way ANOVA). $\mathrm{d}_{f}$ also correlated significantly with lactate and $\mathrm{pH}$ (Pearson correlation coefficient 0.479 and -0.675 respectively, $p<0.05$ ).

Conclusions: DKA patients at presentation have a densely organising less permeable thrombogenic clot microstructure as evidenced by high $\mathrm{d}_{f}$. These structural changes are due to a combination of dehydration and a profound metabolic acidosis, which was reversed with treatment. These changes were not mirrored in standard clinical markers of thrombogenicity.

Key words: Diabetic ketoacidosis (DKA); haemorheology; fractal dimension; gel point. 


\section{Introduction}

Diabetic ketoacidosis (DKA) is a life-threatening emergency caused by the absence of insulin leading to severe metabolic acidosis and dehydration. It is more common in Type 1 diabetes mellitus (DM), however it may occur in patients with Type 2 DM. Severe metabolic acidosis is caused by enhanced breakdown of fat leading to an increase in serum fatty acids subsequently metabolised to ketones (acetoacetic acid and $\beta$-hydoxybutyricacid) in the liver. Dehydration results from osmotic diuresis associated with hyperglycaemia [1]. Therefore, the treatment of DKA is insulin and fluid replacement [2]. DKA is associated with a very high mortality rate of $5.2 \%$ for a single admission and $23.4 \%$ for recurrent admissions [3].

It is estimated that the fluid loss in DKA is approximately 6-9 litres [4]. Dehydration can lead to an increase in whole blood viscosity [5] and thereby increased bioavailability of blood coagulation proteins and platelets. In addition, dehydration can impair microcirculation [6], blood rheology and blood composition [7]. These changes can lead to a hypercoagulable state increasing the risk of thrombosis [8, 9]. A previous study has demonstrated that patients with DKA have reduced Protein C activity (reduced fibrinolysis), low free Protein $S$ and an increase in VWF (Von Willebrand factor) antigen activity [9]. In addition, it has been shown that extracellular acidosis down-regulates most platelet function and increases the neutrophil mediated inflammatory response [10]. However, the balance between thrombogenicity and hypercoagulability and the effect of DKA on the coagulation system and clot microstructure is poorly understood.

One of the widely recognised complications of DKA is the potential for developing venous or arterial thrombosis. There are many published case reports, mainly in children that are associated with central line placement. However, apart from case reports, there is limited evidence which has shown what effect a severe metabolic acidosis and its treatment has on thrombogenicity and clot quality in the first 24 hours. The overall risk for developing venous thromboembolism associated with diabetic hyperosmolarity during an episode is 1.7\% [11]. In other non-ketotic conditions severe dehydration may lead to profound changes in coagulation [12]. In addition, it has also been shown in in-vitro studies in healthy individuals that the 
artificial alteration of $\mathrm{pH}$ may have an effect on clot mass and development $[13,14]$. However, in the acute setting the use of conventional coagulation biomarkers such as PT (prothrombin time) and aPTT (activated partial thromboplastin time) do not reflect the global coagulation picture nor coagulation defects and its final outcome on clot quality [15-17]. A novel functional biomarker namely fractal dimension $\left(\mathrm{d}_{f}\right)$ can be used to quantify the quality and arrangement of clot microstructure. $\mathrm{d}_{f}$ is measured using rheological methods in whole blood. Previous studies have demonstrated that $\mathrm{d}_{f}$ can detect both hypo and hypercoagulable changes in several acute vascular inflammatory conditions. In addition, previous studies has shown that in diseases where vascular changes and flow are altered this biomarker measures variation in the strength and elasticity of the clot's microstructure. This feature is associated with the clot's resistance to breakdown and associated with poorer outcome. Furthermore, $\mathrm{d}_{f}$ has also been validated against treatment were correction of the underlying disease process is associated with a return to a more loosely arranged clot microstructure [19-22]. In this study we measured throughout the acute phase in the first 24 hours the potential effects of thrombogenecity in DKA and also the effect of standard treatment on clot development and its characteristics. We compared these changes with standard kinetic and viscoelastic measurements used in the clinical setting.

\section{Methods}

\section{Study design}

This prospective observational study on 15 patients was carried out in the Emergency Department and Intensive Care Department of a large teaching hospital. This study had full ethical approval from the South West Wales Research Ethics Committee (07/WMW02/34). From patients with capacity, an informed 2-stage written consent was obtained and for those who lacked capacity, an assent was obtained from a personal or legal representative.

\section{Patients}


Fifteen adult patients (>18 years) presenting with a clinical diagnosis of diabetic ketoacidosis (Figure 1) were recruited within the Emergency Department from October 2011 to March 2014. DKA was diagnosed in patients who met the following criteria; capillary blood glucose $>11 \mathrm{mmol} / \mathrm{L}$, capillary ketones $>3 \mathrm{mmol} / \mathrm{L}$ or urinary ketones $>2 \mathrm{mmol} / \mathrm{L}$ and venous $\mathrm{pH}<7.3$ or venous bicarbonate $<18 \mathrm{mmol} / \mathrm{L}$. $A$ control group of 15 healthy volunteers from a similar demographic population group and matched for gender and age were recruited. All healthy volunteers were fully screened to ensure that they were not on any medication or disease process that either affect or alter coagulation profile or platelet function. Patients who were on anticoagulant therapy or had any disease that affects the coagulation profile e.g. renal failure, liver disease were excluded. All the patients received the standard treatment based on hospital guidelines for managing DKA.

\section{Blood sampling}

Blood samples were collected at three time points: 0 hour (at presentation to the Emergency Department), 2-6 hours and 24 hours atraumatically using a large bore needle. The initial $5 \mathrm{mls}$ of blood was discarded to avoid changes in the coagulation system that may be activated by injury to the blood vessel.

\section{Fractal Analysis of clot microstructure}

$6.6 \mathrm{mls}$ of whole, unadulterated blood was transferred to the double concentric cylinder geometry on an AR-G2 controlled stress rheometer (TA Instruments, New Castle, DE, USA) at a temperature of $37^{\circ} \mathrm{C}\left( \pm 0.1^{\circ} \mathrm{C}\right)$. The blood sample was then subjected to a shear stress at frequencies of $0.2 \mathrm{~Hz}, 0.4309 \mathrm{~Hz}, 0.9283 \mathrm{~Hz}$ and $2 \mathrm{~Hz}$ and the phase angle $(\delta)$ was measured with respect to time (s).The gel point analysis was obtained graphically from which the $d_{f}$ can be determined as has been described previously [19-22]. The relationship between $d_{f}$ and clot mass at the gel point was assessed using a previously described computer model of random fractal aggregate growth and the relative normalised mass of the structure that is formed $[23,24]$. This model of the relationship between $d_{f}$ vs. clot mass is shown in Figure 1.

Multiplate (platelet aggregometry) 
$3 \mathrm{mls}$ of blood was collected in a hirudin blood collecting tube containing recombinant hirudin: $>15$ ug/mL (Verum Diagnostica, Munich, Germany) as per manufacturer's instructions to perform platelet analysis. $300 \mu \mathrm{L}$ of hirudinised blood was mixed with an equal volume of normal saline in the multiplate test cell and was then incubated at $37^{\circ} \mathrm{C}$ for 3 minutes. Three agonists: 1) Adenosine diphosphate (ADP test, Verum Diagnostica $\mathrm{GmbH}$ ), 2) Arachadonic acid test of cyclooxygenase activity (ASPI test, Verum Diagnostica $\mathrm{GmbH})$, 3) Collagen (COL test, Verum Diagnostica $\mathrm{GmbH}$ ) were then used to activate the samples. The area under the curve measurements (arbitrary units) were used for aggregometry measurements. The normal ranges were ADP test: 57 to $113 \mathrm{U}$, ASPI test: 71 to $115 \mathrm{U}$ and COL test: 72 to 125 [25, 26]. Plateletcrit was not adjusted before aggregation measurements.

\section{Full blood count and coagulation}

$4 \mathrm{mls}$ of the blood sample were collected into a plastic, full-draw dipotassium EDTA (K2 EDTA 7.2mg) vacutainer (Becton, Dickinson and Company, UK, Ref: 367839) and a full blood count performed (FBC) within 2 hours. Sysmex XE 2100 (Sysmex UK, Milton Keynes, UK) automated haematology analyser was used to analyse the FBC.

$3.5 \mathrm{mls}$ of blood samples were collected into a $3.2 \%(0.109 \mathrm{~mol} / \mathrm{l})$ sodium citrate vacutainer (Greiner Bio-One $\mathrm{GmbH}$, Austria, Ref: 454327) to analyse standard markers of coagulation (PT, aPTT and fibrinogen using Sysmex CA1500) and markers of fibrinolysis (D-dimer using TriniLIA Auto-D-dimer ${ }^{\circledR}$ turbidimetric assay). Factor VIII activity was determined by an aPTT based one-stage assay, using appropriate factor deficient plasma and Actin FS aPTT reagent (Siemens Healthcare Diagnostics Products $\mathrm{GmbH}$, Marburg, Germany).

\section{Rotational thromboelastometry (ROTEM)}

$3.5 \mathrm{mls}$ of blood samples were collected into a sodium citrate tube to analyse inflammatory markers such as PCT (Procalcitonin), TNF-a (Tumour Necrosis Factor), IL-6 (Interleukin) and E-Selectin. ELISA (enzyme-linked immunosorbent assay) kits used platelet poor plasma as instructed by the manufacturer. $600 \mu \mathrm{l}$ of blood was used to perform ROTEM using ROTEM ${ }^{\circledR}$ delta. 


\section{Statistical analysis}

Statistical analysis was carried out with the Statistical Package for Social Sciences (SPSS) for Windows, version 22.0 (Armonk, NY: IBM Corp.). Values are reported as mean and standard deviation or median and interquartile range. To assess differences in the frequency distribution of nominal data parameters across groups, Pearson's chi-squared test was used. Student's T-test was used to assess mean differences in normally distributed data whereas Mann-Whitney was used to determine differences in non-normally distributed data. One-way ANOVA was used to determine differences between more than 2 groups. Data normality was assessed using Shapiro-Wilk test.

\section{Results}

Fifteen patients with diabetic ketoacidosis were included in the study and fifteen healthy volunteers were recruited as a matched control.

\section{Demographics}

The baseline characteristics of DKA patients are summarised in Table: 1.

\section{$\mathrm{pH}$ and $\mathrm{d}_{f}$}

Mean $d_{f}$ in the healthy control group was $1.74 \pm 0.03$. A significantly elevated $d_{f}$ of $1.78 \pm 0.07$ was observed in patients with DKA on admission (Figure 2). The mean $\mathrm{pH}$ on admission was $7.14 \pm 0.13$ and the lactate was $3.6 \pm 2.0 . \mathrm{d}_{f}$ changed significantly in response to standard treatment (intravenous fluids and insulin infusion) and was reduced to $1.68 \pm 0.09$ (2-6hrs), followed by $1.66 \pm 0.08$ at 24 hours $\left(p<0.002\right.$ One-way ANOVA). $d_{f}$ also correlated significantly with lactate and $\mathrm{pH}$ (Pearson correlation coefficient 0.479 and -0.675 respectively, $p<0.05$, Figure 2).

\section{Full Blood Count and Coagulation}

Haemoglobin, haematocrit and platelets were high during the initial presentation and this might be due to haemo-concentration due to dehydration. With fluid replacement the levels normalise, however it was not statistically significant for haemoglobin and haematocrit. The change in platelet count was statistically significant [Table 2]. PT, 
APTT and Fibrinogen levels were not deranged at initial presentation of DKA patients and with standard treatment there were no significant changes even with haemodilution [Table: 2].

\section{Platelet aggregometry}

The multiplate (whole blood impedance aggregometry) analysis using ADP (adenosine diphosphate), ASPI (arachidonic acid) and COL (collagen) agonists showed an initial increased activity over all time points as described in previous studies. However, this has not reached statistically significant changes in platelet aggregation [Table 3] even though there were significant reductions in the platelet count.

\section{ROTEM}

ROTEM was used to measure clot volume and mass as a standard clinical viscoelastic technique. There were no significant changes in CTINTEM (clotting time), CFINTEM (clot formation time) and MCFINTEM (maximum clot firmness). INTEM being intrinsic haemostasis system and EXTEM means extrinsic haemostasis system. Both the LI60INTEM (lysis index after 60 minutes) and LI60EXTEM were statistically significant (Table 4).

\section{D-dimer and inflammatory markers}

No statistical difference between D-dimer and other inflammatory markers was observed in the healthy and DKA groups (Table 5).

\section{Discussion}

DKA is a common medical emergency associated with severe metabolic acidosis and dehydration and if untreated or not addressed urgently has high mortality. With standard treatment such as fluid replacement and administration of insulin, the $\mathrm{pH}$ and metabolic profile should significantly improve and normalise over 24 hours. It is imperative therefore that clinicians have accurate, reproducible and validated biomarkers that urgently assess the changes in DKA's pathophysiology, occurring over the course of treatment. 
One of the main complications of DKA in the first 24 hours is thromboembolic and this risk is maintained until discharge. In this study, we demonstrate that in patients who present with DKA, the conventional biomarkers of clotting do not change during the first 24 hours and there is no indication of a thrombotic state. All the patients followed standard protocol of fluid replacement and insulin with the aim of reducing blood sugar and correcting dehydration. The standard guideline for fluid replacement is $6 \mathrm{~L}$ of crystalloid over 19 hours [26] and more if clinically indicated. All patients responded well to fluid replacement as indicated by a reduction in haematocrit, haemoglobin and fibrinogen from a high to normal limits. None of the patients had any underlying acute inflammatory or coagulopathy conditions as mirrored by normal inflammatory profile (CRP, IL6 and 8, E- selectin, Procalcitonin, Factor VIII) before and after treatment. Therefore, it is arguable that DKA in these patients does not show pro-inflammatory features but DKA induces some of the stress related physiological parameters of the SIRS criteria (Systemic Inflammatory Response Syndrome) most commonly tachycardia and tachypnoea.

The primary clot microstructure of blood clots consists of entangled and branching fibrin fibres. The thinner fibres have more branch points compared to thicker fibres. There is a linear relationship between $d_{f}$ and the amount of fibrin mass that is structurally organised within the normal blood clot [23, 24]. Our study demonstrates that the patients who were admitted with DKA had a tight fibrin clot structure (as indicated by high df $1.78 \pm 0.07)$. The mean $d_{f}$ in the healthy control group $(n=15)$ was $1.74 \pm 0.03$ and was comparable to that published in previous studies of healthy volunteers [16]. In previous studies an increase in $\mathrm{d}_{f}$ was associated with highly dense fibrin clots which indicate a hypercoagulable state [26, 30, 31] and a decrease in $d_{f}$ was associated with less dense fibrin clots indicating a hypocoagulable state $[31,32]$. In contrast the standard kinetic markers, PT/ APTT as well as D-dimer did not have statistical change throughout the management, which would indicate the absence of clotting activation or evidence of a clot breakdown as seen by the Ddimer result. Interestingly there was a slight but non-significant increase in platelet activity, but it did not reach statistical significance and returned rapidly to normal with treatment. There was significant reduction in the platelet count over 24 hours, which may be due to haemodilution from fluid replacement. We assessed clot mass using 
standard thromoelastography. Although there was a slight reduction in clot mass and its development, CF/ CFT/ MCF that are indicators of clotting interestingly remained within normal limits. Only significant change we have seen was an increase in lysis time, however, it remained in normal range. Although ROTEM showed very little change in MCF and clot mass over 24 hours, the $\mathrm{d}_{f}$ showed a consistent and significant decrease in the mechanical strength of the clot. The ability of $d_{f}$ to show accurate and specific changes in clot strength and mechanical properties as compared to other biomarkers were previously observed in septic shock patients [32].

The effect of low pH in clot microstructure has previously been attempted mainly in laboratory studies in non-physiological conditions $[14,15]$. In this study, it was difficult to assess the effect of $\mathrm{pH}$ alone because DKA is characterised by both low $\mathrm{pH}$ and severe dehydration. As severe dehydration would have altered blood flow leading to increased thrombotic risk, we suspect that although $\mathrm{pH}$ may have an effect on clot microstructure as discussed in other studies, the two will have an added effect in abnormal clot development if untreated. It was demonstrated that both $d_{f}$ and clot microstructure decreases with haemodilution in a previous study [33].

Follow up showed all patients were treated appropriately and conventionally. In this study, the combination of dehydration and low $\mathrm{pH}$ lead to a tight and mechanically strong clot, which changed with appropriate treatment, which was opposite to what was observed in conventional markers and ROTEM. The ability of $d_{f}$ as a marker of clot microstructure is the summation of the global pathway of coagulation activation and therefore may be a more sensitive and global marker of haemostasis. This study gives further evidence of the importance of a new biomarker and further studies are required to validate its use further. In summary, in this study there is no indication of thrombogenicity in DKA patients if treated appropriately. However, this does not apply to the patient who gets admitted to the ward, because other factors such as comorbidities and immobilisation may increase VTE episodes.

This study has a number of limitations. Firstly, this was a subgroup analysis of a larger study. Secondly, this was a single centre prospective observational study, 
which was not powered for any clinical outcome, but was mechanistic in design. However, this study determines for the first time an association between changes in $\mathrm{pH}$ observed in DKA and mechanical clot properties. Further studies are required to determine how these effects may arise.

\section{Conclusions}

We believe that this is the first study, which describes changes in clot microstructure associated with the changes in $\mathrm{pH}$ in metabolic acidosis. We show how acute physiological changes such as dehydration and $\mathrm{pH}$, altered capillary blood flow and viscosity affecting clot microstructure and its changing characteristics to treatment. We also demonstrated that $\mathrm{d}_{f}$ was responsive to treatment and that it has the potential to act as a biomarker of clot microstructure and thrombogenicity during DKA and its therapeutic intervention. These microstructural changes are highly relevant to thrombotic changes in many diseases such as DKA. Further studies are required to fully understand how the metabolic changes in DKA regulate $\mathrm{d}_{f}$ and hence thrombogenic events.

\section{Authors' contributions}

PAE conceived the study. GD and PAE designed and coordinated the study. SP drafted the article and interpreted the data. GD \& SP recruited the patients and collected blood samples. GD and MJL performed the rheology tests. SP and RHKM performed the statistical analyses and interpreted the data. JW, JS, KH and PRW revised the manuscript critically for important intellectual content. All authors read and approved the final manuscript.

\section{Funding}

This study was funded by the National Institute for Social Care and Health Research (NISCHR).

\section{Disclosure of Interests}


PAE and PRW have signed the International Committee of Medical Journal Editors (ICMJE) form for declaration of interest. All other authors declare no competing conflicts of interest.

\section{References:}

[1] Gosmanov AR, Gosmanova EO, Dillard-Cannon E. Management of adult diabetic ketoacidosis. Diabetes, Metabolic Syndrome and Obesity: Targets and Therapy. 2014;7:255-264.

[2] Palmer B, Clegg D. Electrolyte and Acid-Base Disturbances in Patients with Diabetes Mellitus. NEJM. 2015; 373;6 (548-559).

[3] Gibb FW, Teoh WL, Graham J, Lockman KA. Risk of death following admission to a UK hospital with diabetic ketoacidosis. Diabetologia. 2016;59(10):2082-7.

[4] Nyenwe EA, Kitabchi AE. Evidence-based management of hyperglycemic emergencies in diabetes mellitus. Diabetes Res Clin Pract. 2011;94(3):340351.

[5] Holsworth RE Jr, Cho YI, Weidman J. Effect of hydration on whole blood viscosity in firefighters. Altern Ther Health Med. 2013 Jul-Aug;19(4):44-9.

[6] Bruno RR, Masyuk M, Muessig JM, Binneboessel S, Bernhard M, Bäz L, Franz M, Kelm M, Jung C. Sublingual microcirculation detects impaired perfusion in dehydrated older patients. Clin Hemorheol Microcirc. 2020 August 12. doi: 10.3233/CH-200859.

[7] Tikhomirova IA, Muravyov AV, Levin VN. Clin Hemorheol Microcirc. Major alterations in body fluid status and blood rheology. 2002;26(3):195-8.

[8] Kelly J, Hunt BJ, Lewis RR, Swaminathan R, Moody a., et al. (2004) Dehydration and venous thromboembolism after acute stroke. QJM - Mon J Assoc Physicians 97: 293-296. doi:10.1093/qjmed/hch050. 
[9] Prandoni $P$ (2006) Acquired risk factors of venous thromboembolism in medical patients. Pathophysiol Haemost Thromb 35: 128-132. doi:10.1182/asheducation-2005.1.458.

[10] Carl GF, Hoffman WH, Passmore GG, Truemper EJ, Lightsey AL, Cornwell PE, Jonah MH. Diabetic Ketoacidosis Promotes a Prothrombotic State 2003. Endocrine Research. 29 (1):73.

[11] Etulain, Negrotto et.al Acidosis downregulates platelet haemostatic functions and promotes neutrophil proinflammatory responses mediated by platelets. Thrombosis and Haemostasis. 2012: 107/1 (Jan) pp. 1-19.

[12] Keenan CR, Murin S, White RH. High risk for venous thromboembolism in diabetics with hyperosmolar state: comparison with other acute medical illnesses. J Thromb Haemost. 2007 Jun;5(6):1185-90.

[13] Dmitrieva NI, Burg MB. Elevated sodium and dehydration stimulate inflammatory signaling in endothelial cells and promote atherosclerosis. PLoS One. 2015 Jun 4;10(6):e0128870. doi: 10.1371/journal.pone.0128870. eCollection 2015.

[14] Engström M, Schött U, Romner B, Reinstrup P. Acidosis impairs the coagulation: A thromboelastographic study. J Trauma. 2006;61(3):624-628. doi:10.1097/01.ta.0000226739.30655.75.

[15] Gissel M, Brummel-Ziedins KE, Butenas S, Pusateri AE, Mann KG, Orfeo T. Effects of an acidic environment on coagulation dynamics. J Thromb Haemost. 2016;14(10):2001-2010. doi:10.1111/jth.13418.

[16] Lipets EN, Ataullakhanov FI (2015) Global assays of hemostasis in the diagnostics of hypercoagulation and evaluation of thrombosis risk. Thromb J $13: 4$

[17] Meybohm P, Zacharowski K, Weber CF (2013) Point-of-care coagulation management in intensive care medicine. Crit Care 17:218.

[18] Favaloro EJ, (Adcock) Funk DM, Lippi G (2012) Pre-analytical variables in coagulation testing associated with diagnostic errors in hemostasis. Lab Med 43:1-10.

[19] Lawrence MJ, Marsden N, Mothukuri R, Morris RHK, Davies G, Hawkins K, Curtis DJ, Brown MR, Williams PR, Evans PA (2016) The effects of temperature on clot microstructure and strength in healthy volunteers. Anesth Analg 122:21-26.

[20] Evans PA, Hawkins K, Morris RHK, Thirumalai N, Munro R, Wakeman L, Lawrence MJ, Williams PR (2010) Gel point and fractal microstructure of incipient blood clots are significant new markers of hemostasis for healthy and anticoagulated blood. Blood 116:3341-3346. 
[21] Evans PA, Hawkins K, Lawrence M, Williams RL, Barrow MS, Thirumalai N, Williams PR (2008) Rheometry and associated techniques for blood coagulation studies. Med Eng Phys 30:671-679 17.

[22] Evans PA, Hawkins K, Lawrence M, Barrow MS, Williams PR, Williams RL (2008) Studies of whole blood coagulation by oscillatory shear, thromboelastography and free oscillation rheometry. Clin Hemorheol Microcirc 38:267-277.

[23] Curtis DJ, Brown MR, Hawkins K, Evans PA, Lawrence MJ, Rees P, Williams PR (2011) Rheometrical and molecular dynamics simulation studies of incipient clot formation in fibrin-thrombin gels: an activation limited aggregation approach. J Nonnewton Fluid Mech 166:932-938 19.

[24] Brown MR, Curtis DJ, Rees P, Summers HD, Hawkins K, Evans PA, Williams PR (2012) Fractal discrimination of random fractal aggregates and its application in biomarker analysis for blood coagulation. Chaos Solit Fractals 45:1025-1032.

[25] Davies GR, Mills GM, Lawrence M, Battle C, Morris K, Hawkins K, Williams PR, Davidson S, Thomas D, Evans PA (2014) The role of whole blood impedance aggregometry and its utilisation in the diagnosis and prognosis of patients with systemic inflammatory response syndrome and sepsis in acute critical illness. PLoS One. 2014 Sep 30;9(9):e108589.

[26] Sabra A, Stanford S, et al. (2016). Assessment of platelet function in patients with stroke using multiple electrode platelet aggregometry: a prospective observational study. BMC Neurology (2016) 16:254.

[27] The management of Diabetes Ketoacidosis in Adults. https://www.diabetes.org.uk/resources-s3/2017-09/Management-of-DKA241013.pdf accessed on 3rd October 2019.

[28] Sabra A, Lawrence J, et al. (2017). Characterisation of clot microstructure properties in stable coronary artery disease. Open Heart 2017;4:e000562. doi:10.1136/openhrt-2016-000562.

[29] Lawrence M, Sabra A, et al. (2015). Fractal dimension: A novel clot microstructure biomarker use in ST elevation myocardial infarction patients. Atherosclerosis240 (2015) 402- 407.

[30] Davies NA, Harrison NK, Morris RHK, Noble S, Lawrence MJ, DSilva LA, Broome L, Brown MR, Hawkins KM, Williams PR, Davidson S, Evans PA (2015) Fractal dimension ( $d f$ ) as a new structural biomarker of clot microstructure in different stages of lung cancer. Thromb Haemost 114:1251-1259. 
[31] Stanford SN, Sabra A, DSilva LA, Lawrence M, Morris R, Storton S, Brown M, Evans V, Hawkins K, Williams P, Davidson SJ, Wani M, Potter JF, Evans PF (2015) The changes in clot microstructure in patients with ischaemic stroke and the effects of therapeutic intervention: a prospective observational study. BMC Neurol 15:35.

[32] Davies GR, Pillai S, Lawrence M. et al. The effect of sepsis and its inflammatory response on mechanical clot characteristics: a prospective observational study. Intensive Care Med. 2016 Dec; 42(12):1990-1998.

[33] Lawrence $M$, Kumar S et al. A new structural biomarker that quantifies and predicts changes in clot strength and quality in a model of progressive haemodilution. Thrombosis Research 134 (2014) 488-494. 


\section{Tables}

Table: 1. DKA patient baseline characteristics

\begin{tabular}{|c|l|}
\hline Age, mean \pm SD & $45.6 \pm 14.2$ \\
\hline Sex: Male/ Female & $8 / 6$ \\
\hline $\begin{array}{c}\text { Comorbidity } \quad \text { Hypertension } \\
\text { Ischaemic heart disease }\end{array}$ & 3 \\
\hline $\begin{array}{l}\text { Glucose (mmol/L) } \\
\text { pH }\end{array}$ & 3 \\
\hline HCO $(\mathrm{mmol} / \mathrm{L})$ & $44.7 \pm 15.9$ \\
\hline Urea $(\mu \mathrm{mol} / \mathrm{L})$ & $7.1 \pm 0.2$ \\
\hline Creatinine $(\mu \mathrm{mol} / \mathrm{L})$ & $8.9 \pm 5.3$ \\
\hline
\end{tabular}

Values are presented as mean \pm SD or median part from co-morbidities. 
Table: 2. Shows the mean \pm standard deviation SD for df, PT, APTT, Fibrinogen, Platelets, Haemoglobin and HCT at three time points

\begin{tabular}{|c|c|c|c|c|}
\hline & & $\mathbf{N}$ & Mean $\pm S D$ & p-value \\
\hline$d_{f}$ & $\begin{array}{l}\text { Baseline } \\
\text { 2-6 hours } \\
24 \text { hours }\end{array}$ & $\begin{array}{l}12 \\
9 \\
12\end{array}$ & $\begin{array}{l}1.78 \pm 0.07 \\
1.68 \pm 0.09 \\
1.66 \pm 0.08\end{array}$ & 0.002 \\
\hline PT & $\begin{array}{l}\text { Baseline } \\
2-6 \text { hours } \\
24 \text { hours }\end{array}$ & $\begin{array}{l}14 \\
11 \\
13\end{array}$ & $\begin{array}{l}10.94 \pm 1.18 \\
10.97 \pm 1.09 \\
11.26 \pm 0.08\end{array}$ & 0.813 \\
\hline APTT & $\begin{array}{l}\text { Baseline } \\
2-6 \text { hours } \\
24 \text { hours }\end{array}$ & $\begin{array}{l}14 \\
11 \\
13\end{array}$ & $\begin{array}{l}28.24 \pm 6.29 \\
25.43 \pm 2.78 \\
24.22 \pm 2.70\end{array}$ & 0.65 \\
\hline Fibrinogen & $\begin{array}{l}\text { Baseline } \\
\text { 2-6 hours } \\
24 \text { hours }\end{array}$ & $\begin{array}{l}14 \\
11 \\
13\end{array}$ & $\begin{array}{l}3.15 \pm 0.72 \\
3.18 \pm 0.64 \\
3.21 \pm 0.87\end{array}$ & 0.980 \\
\hline Platelets & $\begin{array}{l}\text { Baseline } \\
\text { 2-6 hours } \\
24 \text { hours }\end{array}$ & $\begin{array}{l}15 \\
10 \\
13\end{array}$ & $\begin{array}{l}328.53 \pm 94.28 \\
274.40 \pm 73.73 \\
227.23 \pm 67.97\end{array}$ & 0.008 \\
\hline Haemoglobin & $\begin{array}{l}\text { Baseline } \\
\text { 2-6 hours } \\
24 \text { hours }\end{array}$ & $\begin{array}{l}15 \\
11 \\
13\end{array}$ & $\begin{array}{l}13.51 \pm 2.38 \\
12.53 \pm 2.14 \\
11.74 \pm 1.80\end{array}$ & 0.103 \\
\hline HCT & $\begin{array}{l}\text { Baseline } \\
2-6 \text { hours } \\
24 \text { hours }\end{array}$ & $\begin{array}{l}15 \\
11 \\
13\end{array}$ & $\begin{array}{l}0.42 \pm 0.08 \\
0.38 \pm 0.06 \\
0.35 \pm 0.05\end{array}$ & 0.012 \\
\hline
\end{tabular}


Table: 3. Multiplate analysis with three reagents (ADP- adenosine diphosphate, ASPI- arachidonic acid and COL- collagen agonist at three time points shows there is no significant change in platelet aggregation

\begin{tabular}{|ll|l|l|l|}
\hline & $\mathbf{N}$ & Mean \pm SD & p-value \\
\hline ADPAUC & Baseline & 13 & $95.46 \pm 37.46$ & 0.70 \\
& $2-6$ hours & 11 & $90.09 \pm 24.72$ & \\
& 24 hours & 13 & $69.31 \pm 22.51$ & \\
\hline ASPIAUC & Baseline & 13 & $131.23 \pm 48.91$ & 0.220 \\
& $2-6$ hours & 11 & $117.00 \pm 42.71$ & \\
& 24 hours & 13 & $101.23 \pm 36.40$ & \\
\hline COLAUC & Baseline & 13 & $104.62 \pm 27.66$ & 0.80 \\
& $2-6$ hours & 11 & $95.36 \pm 23.10$ & \\
& 24 hours & 13 & $81.31 \pm 25.52$ & \\
\hline
\end{tabular}

Values reported as mean \pm SD. Area under the curve for ADP test: 57 to $113 \mathrm{U}, \mathrm{ASPI}$ test: 71 to $115 \mathrm{U}$ and COL test: 72 to 125 .

Table: 4. Rotational thromboelastometry at three time points shows that LI60INTEM and LI60EXTEM were statistically significant

\begin{tabular}{|ll|l|l|l|}
\hline & & $\mathbf{N}$ & Mean \pm SD & p-value \\
\hline CTINTEM & Baseline & 14 & $146.21 \pm 26.02$ & 0.953 \\
& $2-6$ hours & 11 & $150.27 \pm 31.45$ & \\
\hline CFTINTEM & Baseline & 13 & $148.08 \pm 39.26$ & \\
& $2-6$ hours & 14 & $64.93 \pm 16.15$ & 0.992 \\
& 24 hours & 11 & $64.27 \pm 13.91$ & \\
\hline MCFINTEM & Baseline & 12 & $64.92 \pm 13.40$ & \\
& $2-6$ hours & 14 & $60.64 \pm 26.00$ & 0.577 \\
& 24 hours & 11 & $68.00 \pm 3.55$ & \\
\hline LI60INTEM & Baseline & 12 & $60.42 \pm 19.52$ & \\
& $2-6$ hours & 12 & $98.00 \pm 1.54$ & $<0.0005$ \\
& 24 hours & 11 & $96.18 \pm 2.93$ & \\
\hline LI60EXTEM & Baseline & 10 & $91.80 \pm 2.94$ & \\
& $2-6$ hours & 12 & $96.42 \pm 1.73$ & $<0.0005$ \\
& 24 hours & 11 & $94.73 \pm 2.90$ & \\
& & 10 & $91.10 \pm 3.63$ & \\
\hline
\end{tabular}


Table: 5. No statistical difference in D-dimer or inflammatory markers at three time points. pH changed significantly with standard treatment over 24 hours

\begin{tabular}{|c|c|c|c|c|}
\hline & & $\mathrm{N}$ & $\begin{array}{l}\text { Mean } \pm \text { SD }\left({ }^{*} \text { denotes }\right. \\
\text { median and IQR) }\end{array}$ & $\mathrm{p}$-value \\
\hline D-Dimer & $\begin{array}{l}\text { Baseline* } \\
2-6 \text { hours* } \\
24 \text { hours }^{\star}\end{array}$ & $\begin{array}{l}11 \\
7 \\
8\end{array}$ & \begin{tabular}{|l|}
$338(97-784)$ \\
$268(78-401)$ \\
$527(495-1042)$
\end{tabular} & 0.092 \\
\hline CRP & $\begin{array}{l}\text { Baseline }^{\star} \\
2-6 \text { hours } \\
24 \text { hours }\end{array}$ & $\begin{array}{l}13 \\
1 \\
0\end{array}$ & $9(4-18)$ & \\
\hline IL8 & $\begin{array}{l}\text { Baseline* }^{\star} \\
2-6 \text { hours* } \\
24 \text { hours }^{\star}\end{array}$ & $\begin{array}{l}9 \\
7 \\
7\end{array}$ & $\begin{array}{l}26(19-51) \\
19(12-21) \\
25(16-32)\end{array}$ & 0.273 \\
\hline E-Selectin & $\begin{array}{l}\text { Baseline } \\
2-6 \text { hours } \\
24 \text { hours }\end{array}$ & $\begin{array}{l}9 \\
7 \\
7\end{array}$ & $\begin{array}{l}45 \pm 27 \\
41 \pm 17 \\
50 \pm 28\end{array}$ & 0.793 \\
\hline$\overline{P C T}$ & $\begin{array}{l}\text { Baseline* }^{\star} \\
2-6 \text { hours* } \\
24 \text { hours }^{\star}\end{array}$ & $\begin{array}{l}9 \\
6 \\
7\end{array}$ & $\begin{array}{l}237(191-343) \\
473 \pm 353 \\
337(178-432)\end{array}$ & 0.700 \\
\hline IL6 & $\begin{array}{l}\text { Baseline* } \\
2-6 \text { hours* } \\
24 \text { hours }^{\star}\end{array}$ & $\begin{array}{l}9 \\
7 \\
5\end{array}$ & $\begin{array}{l}32(8-35) \\
18(5-25) \\
30(21-48)\end{array}$ & 0.441 \\
\hline FVIII & $\begin{array}{l}\text { Baseline } \\
2-6 \text { hours } \\
24 \text { hours }\end{array}$ & $\begin{array}{l}11 \\
8 \\
11\end{array}$ & $\begin{array}{l}359.3091 \pm 184 \\
302.4875 \pm 126 \\
228.4455 \pm 94\end{array}$ & 0.113 \\
\hline $\mathrm{pH}$ & $\begin{array}{l}\text { Baseline } \\
2-6 \text { hours } \\
24 \text { hours }\end{array}$ & $\begin{array}{l}11 \\
6 \\
4\end{array}$ & $\begin{array}{l}7.1409 \pm 0.13 \\
7.2550 \pm 0.05 \\
7.3525 \pm 0.02\end{array}$ & 0.005 \\
\hline
\end{tabular}




\section{Figures}

Figure: 1.The variation of the mass of a random fractal aggregate (RFA) as a function of fractal dimension. The magnitude of the RFA is normalised to the mean of the lowest mean value of df for the three time points of the DKA patients (which was $d_{f}=1.68$ at 24 hour sampling point). The dotted lines represent the mean $d_{f}$ and corresponding normalised mass value for whole blood at: $d_{f}=1.69$, mass $=1.0$; healthy control value $\left(d_{f}=1.74\right.$, mass $\left.=2.0\right)$; and DKA on admission $\left(d_{f}=1.78\right.$, mass $\left.=3.6\right)$.

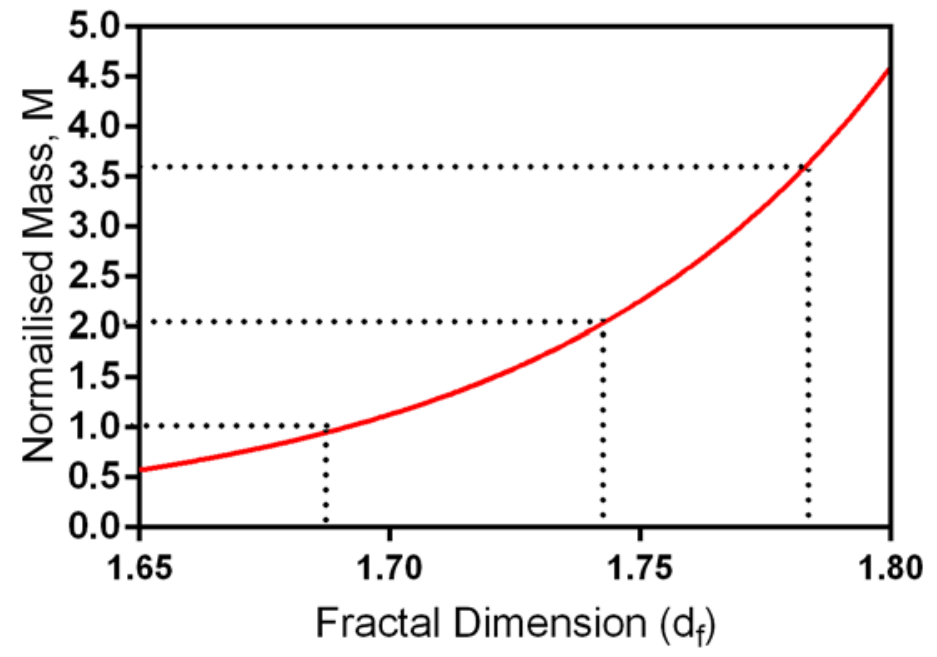

Figure: 2. Mean df in healthy and DKA group. Mean df in the healthy control group was $1.74 \pm 0.03$. An elevated df of $1.78 \pm 0.07$ was observed in patients with DKA on admission. This indicates that DKA patients has tighter clot microstructure.

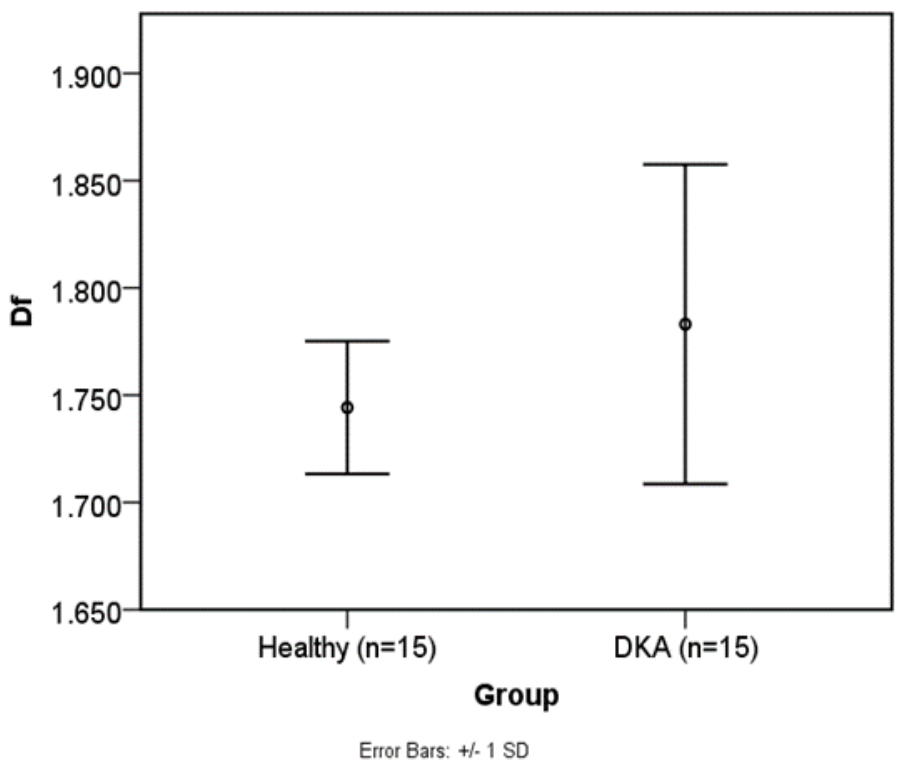


Figure: 3. Shows the change in $\mathrm{pH}$ and $\mathrm{d}_{\mathrm{f}}$ during 24 hour treatment

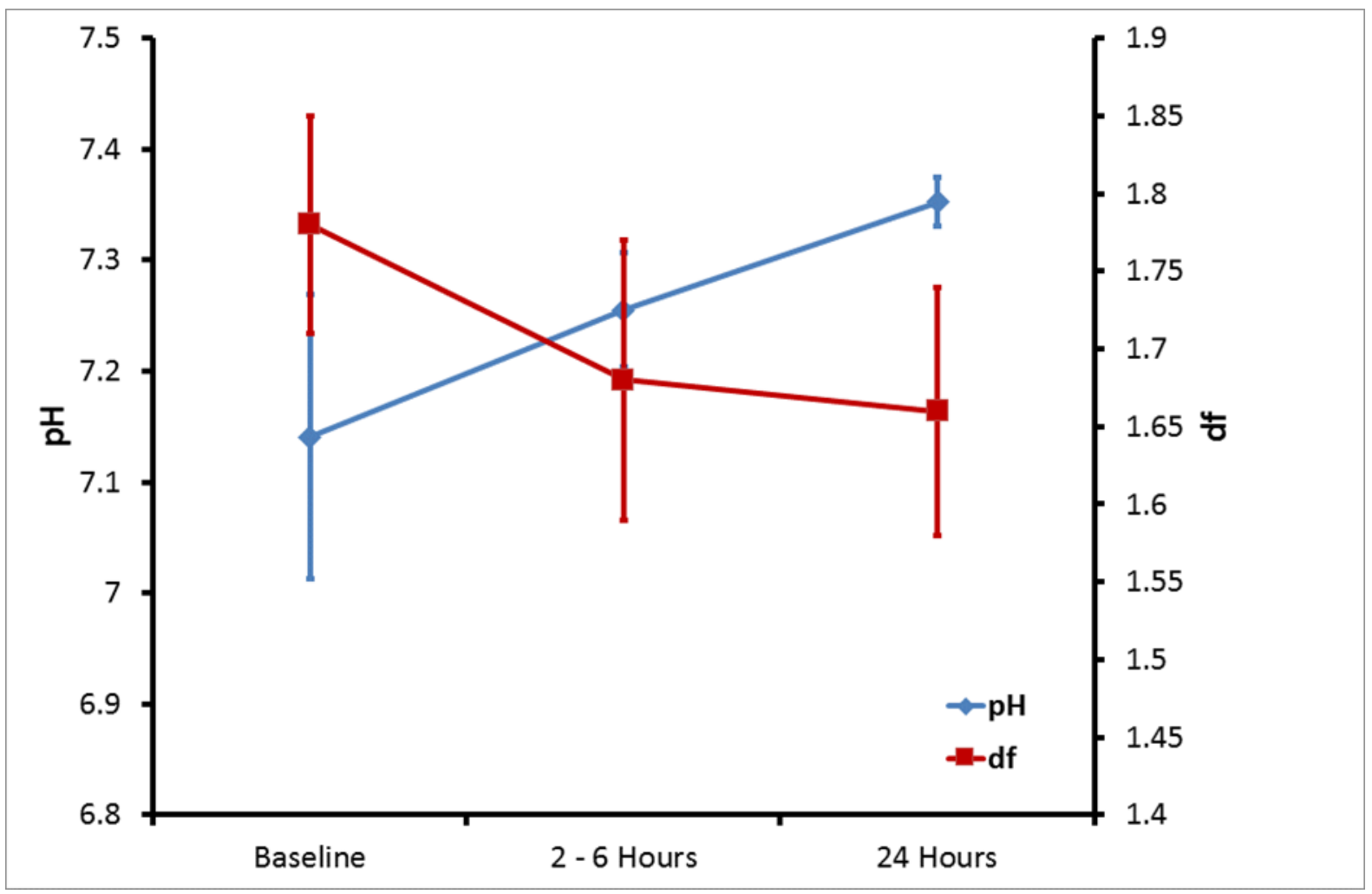

